Revue

Revue de l'histoire des religions

de Ihistoire

des religions

$3 \mid 2018$

Varia

Cédric GIRAUD, Spiritualité et histoire des textes entre Moyen Âge et époque moderne. Genèse et fortune d'un corpus pseudépigraphe de méditations

Paris, Institut d'Études Augustiniennes, 2016

Simon Icard

\title{
OpenEdition
}

Journals

Édition électronique

URL : http://journals.openedition.org/rhr/9076

DOI : 10.4000/rhr.9076

ISSN : 2105-2573

Éditeur

Armand Colin

Édition imprimée

Date de publication : 1 septembre 2018

Pagination : $551-552$

ISBN : 978-2-200-93188-9

ISSN : 0035-1423

Référence électronique

Simon Icard, «Cédric GiRaud, Spiritualité et histoire des textes entre Moyen Âge et époque moderne.

Genèse et fortune d'un corpus pseudépigraphe de méditations », Revue de l'histoire des religions [En ligne]

3 | 2018, mis en ligne le 01 septembre 2018, consulté le 15 janvier 2021. URL : http://

journals.openedition.org/rhr/9076; DOI : https://doi.org/10.4000/rhr.9076

Ce document a été généré automatiquement le 15 janvier 2021.

Tous droits réservés 


\section{Cédric GIRAUD, Spiritualité et histoire des textes entre Moyen Âge et époque moderne. Genèse et fortune d'un corpus pseudépigraphe de méditations}

Paris, Institut d'Études Augustiniennes, 2016

Simon Icard

\section{RÉFÉRENCE}

Cédric GIRAUD, Spiritualité et histoire des textes entre Moyen Âge et époque moderne. Genèse et fortune d'un corpus pseudépigraphe de méditations, Paris, Institut d'Études Augustiniennes, 2016, 538 p., 24,5 cm, $69 €$, ISBN 978-2-85121-281-8.

1 Issu d'un mémoire d'habilitation à diriger des recherches, l'ouvrage étudie un corpus de méditations ayant connu un étonnant destin commun : le Manuale, les Soliloquia et les Meditationes pseudo-augustiniens, les Meditationes pseudo-bernardines, auxquels s'ajoutent, à partir de l'édition d'Henri de Sommal (1608), les Meditationes de Raymond Jordan, alias l'Idiota. La méthode suivie est triplement originale et fait de ce livre une contribution majeure à l'histoire de la spiritualité.

2 Tout d'abord, à rebours du préjugé selon lequel seules compteraient les œuvres authentiques des grands auteurs, Cédric Giraud a pris au sérieux l'importance de pseudépigraphes progressivement rejetés des opera augustinien et bernardin à l'époque moderne. Au vu du nombre considérable de manuscrits et d'éditions imprimées composant leur tradition textuelle, l'expression «classiques de la spiritualité chrétienne » (p. 17) n'est nullement usurpée. L'attribution erronée de ces textes à saint Augustin et à saint Bernard, puis l'entre-deux éditorial qui leur fit poursuivre leur carrière à l'ombre de ces deux figures tutélaires, alors qu'ils étaient reconnus comme apocryphes, ne réduisent pas leur intérêt historique. Tout au contraire, ils en font 
d'excellents révélateurs des évolutions de la spiritualité et de ses présupposés. On est ainsi frappé par l'extrême plasticité d'un corpus indissociable de la pratique méditative et de ses mutations au fil des siècles.

3 Ensuite, l'étude s'inscrit dans le temps long, en couvrant toute l'histoire de ces méditations, de leur naissance au Moyen Âge jusqu'à leur quasi-extinction éditoriale à la fin $\mathrm{du}_{\mathrm{XIX}}{ }^{\mathrm{e}}$ siècle - le sous-titre du livre ne rend d'ailleurs pas vraiment justice à l'extrémité chronologique de l'enquête. Ce parti pris s'avère très fructueux en ce qu'il apporte un éclairage que n'aurait pas permis une série d'études cloisonnées par la distinction canonique des époques, comme on peut le voir de manière exemplaire au sujet du passage des manuscrits aux imprimés. L'un des tours de force de l'ouvrage consiste à offrir au lecteur des mises en contexte aussi précises que pédagogiques sur une si longue durée. Certains passages peuvent ainsi être lus de manière autonome, comme des études de référence sur des sujets aussi divers que la naissance et le développement du genre méditatif au Moyen Âge, l'œuvre critique de Théophile Raynaud ou l'usage du livre de piété dans l'entreprise de restauration religieuse de l'ordre moral. Rares sont les livres dont médiévistes, modernistes et contemporanéistes peuvent faire leur miel. L'ouvrage de Cédric Giraud est de ceux-là.

4 Enfin, l'histoire des textes méditatifs y est considérée comme une contribution à l'histoire de la spiritualité, et non plus comme un simple préalable érudit à celle-ci. Devenu "voie d'accès privilégiée à l'intériorité»(p.17), le livre se révèle aussi signifiant que les doctrines. La matérialité des supports, les variations dans la composition des textes ou leur collection, les travaux de réécriture et de traduction sont autant d'objets d'études qui permettent d'écrire le "récit critique " de ces méditations (p. 474). L'ampleur de l'enquête philologique dans le champ des manuscrits et dans celui des imprimés force le respect, tout comme l'art d'en rendre accessible les résultats sans aucune aridité ni sécheresse, grâce à un style clair et élégant.

\section{AUTEURS}

\section{SIMON ICARD}

Centre national de la recherche scientifique,

Laboratoire d'études sur les Monothéismes, Paris. 